\title{
Metodologia da pesquisa versus pesquisa da metodologia: interfaces da dogmática jurídica na pós-graduação
}

\author{
Research methodology versus research on methodology: of legal doctrine in \\ graduate studies
}

\section{Metodología de la investigación versus investigación de la metodología: interfaces de la dogmática jurídica en el postgrado}

http://dx.doi.org/10.221713/2358-2332.2016.v14.1413 ${ }^{1}$

Elaine Cristina Francisco Volpato, doutora em Direito pela Universidade Federal do Paraná (UFPR), professora adjunta da Universidade Estadual do Oeste do Paraná (Unioeste), Foz do Iguaçu, PR, Brasil. E-mail: elacrisfr@ hotmail.com.

\section{Resumo}

Este estudo investiga, em nível de doutoramento, a "cientificidade" do conhecimento gerado em Direito no Brasil. Acolhe, como principal hipótese de pesquisa a questão metodológica mediante a análise das teses de doutoramento selecionadas produzidas nas Universidade Federal de Minas Gerais, Universidade de São Paulo, Universidade Federal de Santa Catarina, Universidade Federal do Paraná, Universidade do Vale do Rio dos Sinos, Pontifícia Universidade Católica de Minas Gerais, Universidade de Brasília e Pontifícia Universidade Católica do Rio Grande do Sul, num enfoque empírico e não paramétrico. Além da análise baseada na experiência e na observação, instrumentalizada pelo exame de conteúdo, dados secundários da Plataforma Sucupira foram utilizados para completar um retrato pontual do embate pela eficiência de tais programas, descrevendo qualitativamente a facilidade de acesso ao conhecimento gerado institucionalmente.

Palavras-chave: Epistemologia. Doutorado em Direito. Conhecimento Científico.

\section{Abstract}

This study investigates the scientific knowledge generated in Law in Brazil at the doctoral level. Its main research hypothesis, the methodological question by means of the analysis of $\mathrm{PhD}$ theses selected from University of Minas Gerais, University of São Paulo,

\footnotetext{
${ }^{1}$ Como citar: ABNT NBR 6023:2002 e incluir o DOI.
} 
Volpato / Metodologia da pesquisa versus pesquisa da metodologia: interfaces da dogmática jurídica na pósgraduação

Federal University of Santa Catarina, Federal University of Paraná, Vale do Rio dos Sinos University, Pontifical Catholic Uiversity of Minas Gerais, University of Brasília and Pontifical Catholic University of Rio Grande do Sul, in an empirical and non-parametric approach. In addition to the experience- and observation-based analysis, instrumented by the content analysis, secondary data from the Sucupira Platform were used to complete a punctual portrait of the struggle for the efficiency of such programs, describing qualitatively the ease of access to the knowledge generated institutionally.

Keywords: Epistemology. Doctorate in Law. Scientific Knowledge.

\section{Resumen}

Esta investigación estudia, a nivel de doctorado, la "cientificidad" del conocimiento generado en Derecho en Brasil. Acoge, como principal objetivo de la investigación la cuestión metodológica mediante el análisis de las tesis de doctorado seleccionadas en las universidades De la Universidad Federal de Minas Gerais, Universidad de São Paulo, Universidad Federal de Santa Catarina, Universidad Federal de Paraná, Universidad del Valle de Río de los Sinos, Pontificia Universidad Católica de Minas Gerais, Universidad de Brasilia y Pontificia Universidad Católica de Rio Grande do Sul, en un enfoque empírico y no paramétrico. Además del análisis basado en la experiencia y la observación, instrumentalizada por el examen de contenido, datos secundarios de la Plataforma Sucupira han sido utilizados para completar un retrato puntual del embate por la eficiencia de dichos programas, describiendo cualitativamente la facilidad de acceso al conocimiento generado institucionalmente.

Palabras clave: Epistemología. Doctorado en Derecho. Conocimiento Científico.

\section{INTRODUÇÃO}

O conhecimento científico é uma forma colaborativa coletiva para renovar a dinâmica social existente. Por isso, a produção científica derivada das teses de doutorado em Direito deve ser encarada para além de uma formalidade acadêmica que fecha um ciclo de aprendizagem.

Uma tese ou uma produção acadêmica em nível de doutorado, também no Direito, tende a assumir agora um processo contínuo de construção interativa, colaborativa, intensiva e laboriosa de um saber interdependente. É segundo esse viés particular que se coloca para pensar a questão da pesquisa em Direito, em que o trabalhar com o conhecimento jurídico é aplicar os parâmetros da Ciência (nem abaixo, nem acima) disponíveis às comunidades formadas por cientistas.

Este artigo se assenta na reafirmação de valores éticos e na iniciação da pesquisa com qualidade científica, estabelecendo-se em um novo patamar: a autoridade do argumento. Aumentar a cientificidade do estudo do Direito não é um desafio nacional, mas uma carência mundialmente reconhecida. 
Volpato / Metodologia da pesquisa versus pesquisa da metodologia: interfaces da dogmática jurídica na pósgraduação

E, de certo modo, enfrenta o enigma central: "Por que o estudo acadêmico do Direito não se desenvolve de modo científico?" Esta pergunta identifica quanto o jurista (pesquisador acadêmico) ainda não se (pre)ocupa em desenvolver sua teoria central e tampouco prima pela adequada aplicação de métodos de análise de discurso, justificando uma provável falta de proximidade da vivência acadêmica com a realidade da vida social ${ }^{2}$.

Por isso, consciente dos limites tão estreitos deste texto, deseja-se aqui colaborar com um debate novo sobre a importância da metodologia na pesquisa jurídica, tomando essa metodologia como fator indispensável para a qualidade científica. $\mathrm{O}$ problema central desta pesquisa é sintetizar, em parte, aquela inquietante questão, dispondo-se a descrever o panorama qualitativo da pesquisa jurídica nas instituições de pós-graduação reconhecidas por sua excelência em âmbito nacional. Para tanto, o estudo se propõe a analisar a acessibilidade ao acervo de conhecimento produzido no programa e o levantamento da frequência de aspectos fundamentais das teses da amostra selecionada, que se ocupam da temática e das opções metodológicas mais significativas.

O tema, além de muito amplo, é pouco estudado na academia do Direito e possui múltiplas dimensões controversas, dignas de serem debatidas na pós-graduação em Direito. Assim, a problemática foi delimitada em aspectos menos vagos, segundo critérios objetivos precisos: a) adotar por objeto de estudo as pesquisas de doutoramento brasileiras dos programas com excelência nacional, programas atualmente reconhecidos pela Capes e avaliados com nota seis; b) escolher o lapso de tempo restrito (2000 a 2010), delineando o impacto das avaliações trienais externas a que os programas se sujeitaram; c) delimitar, de forma restrita, a dimensão de sua amostra, priorizando a multiplicidade de fatores (quesitos) pesquisados, catalogados em análise de frequência.

Não foi proposta de estudo proceder à leitura, em profundidade, de todas as teses produzidas em cada um dos programas de pós-graduação escolhidos, considerando a absoluta falta de viabilidade prática de uma tarefa desse porte. A redução segura do objeto de pesquisa foi possível mediante o estudo não paramétrico e pela escolha da amostragem não probabilística por conveniência (acidental) ${ }^{3}$ de 70 teses dos programas de doutorado em Direito da Universidade Federal de Minas Gerais, Universidade de São Paulo, Universidade Federal de Santa Catarina, Universidade Federal do Paraná, Universidade do Vale do Rio dos Sinos, Pontifícia Universidade Católica de Minas Gerais, Universidade de Brasília e Pontifícia Universidade Católica do Rio Grande do Sul.

A amostragem por conveniência é o uso de dados que estiverem mais acessíveis, sua aplicação é útil para testar questionários. Ela é normalmente utilizada em pesquisas qualitativas com certas precauções e ressalvas, isto é, sem o objetivo de projeção para demais membros da

\footnotetext{
${ }^{2} \mathrm{O}$ texto retoma algumas das constatações originais do professor Thomas S. Ulen (2014) e sintetizadas na obra Direito e Economia em dois mundos, cujas credenciais completas estão nas referências do presente texto.

${ }^{2}$ De acordo com Malhotra (2001), tal técnica procura estudar os elementos disponíveis e representativos de uma população de interesse, nela a seleção das unidades amostrais é deixada a cargo do pesquisador, sem comprometer a "cientificidade" do artifício, na medida em que apenas limita a amplitude de suas conclusões.
} 
Volpato / Metodologia da pesquisa versus pesquisa da metodologia: interfaces da dogmática jurídica na pósgraduação

população. Para fins estatísticos, esta abordagem é utilizada por ser expediente prático e rápido. Com baixa margem de erro, na medida em que a população estudada é dotada de características homogêneas, as técnicas mais rigorosas de amostragem estatística a elas poderiam não ser aplicadas, quer por razões de ordem material (os dados não podem ser acessíveis), quer por motivos econômicos, quer pela pouca disponibilidade de tempo (Malhotra, 2001).

A seleção tornou possível construir um banco de dados pessoal com as teses disponibilizadas pelos mencionados programas de pós-graduação, assim facilitando a leitura e a decodificação dos elementos significativos. A partir da identificação dos elementos de pesquisa, passou-se ao registro em fichas, com contabilização e interpretação dos dados coletados com a confecção de vários gráficos comparativos.

Para evitar um desequilíbrio comprometedor, quanto ao número de registros de cada programa de doutorado, as teses foram selecionadas segundo a conveniência e a disponibilidade dos textos pelos programas, conforme os seguintes critérios:

a) uma tese por linha de pesquisa;

b) uma tese por ano (considerado o lapso de 2000-2010);

c) um banco de dados com a conciliação dos critérios anteriores; e

d) uma eleição de textos com o conteúdo digital disponibilizado em site vinculado ao programa de pós-graduação estudado.

Ainda para elucidar os parâmetros de escolhas, é oportuno fazer nota que a relação de teses premiadas pelas Capes, nas três categorias atualmente contempladas, mostrou-se inviável, pois a premiação teve início em 2006 e a relação dos premiados só está digitalmente disponível a partir dos premiados de 2010.

Estabelecidos os critérios, relata-se a visita aos sites dos programas para a constituição de um acervo pessoal individualizado, por programa e por ano, que facilitassem a leitura sistemática. Passou-se então para a específica análise dos critérios avaliados, na temática e na metodologia, apresentando-se, ao fim, as conclusões e os resultados da pesquisa empírica efetuada.

Durante a construção das respostas, para complementar os dados levantados, consultaram-se, novamente, duas importantes fontes de informações on-line: Plataforma Lattes e a Plataforma Sucupira. Com a ajuda de tais bancos de dados públicos, foi possível aferir o tempo médio de titulação e a produção científica dos doutores estudados.

\section{AS PROBLEMÁTICAS ENCONTRADAS NA AMOSTRA}

Constatou-se que, quanto à temática das teses lidas, os problemas afetos à vivência profissional do jurista foram os mais pesquisados, correspondendo a 58 títulos. Questões de Teoria de Direito e de Filosofia de Direito totalizam, em conjunto, apenas 12 teses. No Gráfico 1, visualiza-se o percentual de pesquisa dos temas citados: 
Volpato / Metodologia da pesquisa versus pesquisa da metodologia: interfaces da dogmática jurídica na pósgraduação

\section{Gráfico 1 - Problemas de pesquisa}

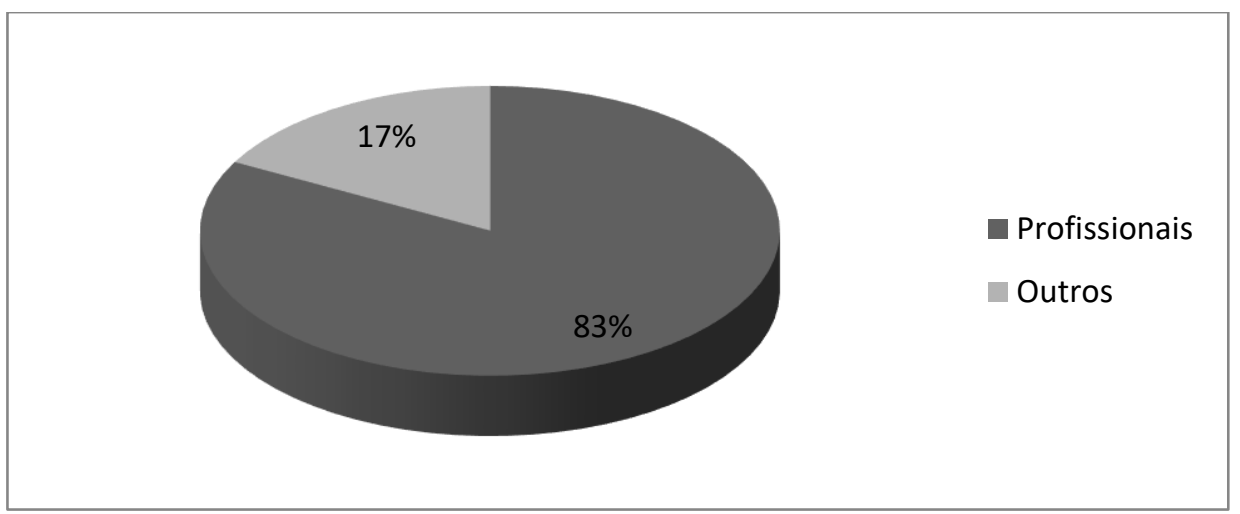

Fonte: Elaboração própria a partir das pesquisas consultadas.

Os resultados apurados remetem ao problema do formalismo jurídico na aprendizagem do Direito, muitas vezes restrito ao aprendizado de códigos, sem acompanhar as sucessivas transformações históricas da sociedade e das instituições. Esses são fatores peculiares, para alguns estudiosos da pedagogia jurídica, estruturalmente ligados à má qualidade do ensino jurídico, inclusive na pós-graduação (FARIA, 2006).

A pesquisa jurídica acadêmica apenas coloca em termos quantificáveis esse hiato entre a teoria em Direito e a realidade social brasileira atual. Então, ainda são relativamente comuns cursos que tratam a ordem jurídica como se ela não tivesse sofrido qualquer alteração estrutural, confundindo-se, segundo José Eduardo Faria (2006, p. 3), com "[...] a elaboração de uma dissertação ou tese com a redação de projetos de lei pretensamente capazes de resolver problemas socioeconômicos cujo alcance e implicações ainda nem sequer são conhecidos".

O desenvolvimento das pesquisas jurídicas implica, antes de tudo, falar em transformação metodológica, com mudança das práticas pedagógicas da sala de aula e do ensino de disciplinas concernentes ao método e à pesquisa, de modo a estimular o "espírito científico", instigado a buscar respostas a sucessivas questões.

O necessário, efetivamente, é romper, de modo bastante peculiar, com conceitos tradicionais de ciência jurídica, estreito em demasia, em sociedades tão complexas como a nossa. A "ciência jurídica", como pensamento tecnológico sobre o sistema normativo vigente, restringe as mentes dos pesquisadores e da pesquisa jurídica. Esse é um fenômeno muito bem sintetizado por Diniz, na medida em que afirma:

[...] a ciência jurídica consiste no pensamento tecnológico que busca expor metódica, sistemática e fundamentadamente as normas vigentes de determinado ordenamento jurídico-positivo, e estudar os problemas relativos a sua interpretação e aplicação, procurando apresentar soluções viáveis para os possíveis conflitos, orientando como devem ocorrer os comportamentos procedimentais que objetivam decidir questões conflitivas. (DINIZ, 1988, p. 198). 
Volpato / Metodologia da pesquisa versus pesquisa da metodologia: interfaces da dogmática jurídica na pósgraduação

Como apregoa Neves (1993), é tempo propício para romper com padronização. Para esse pensador, a metodologia jurídica é sempre ou de um direito codificado, ou de uma jurisprudência (um case law).

A leitura jurídica tradicional, que precisa necessariamente se descolar da realidade, é traço ainda presente nas pesquisas de doutoramento nacionais, excessivamente baseada em preceitos normativos, estimando que estes possam dar conta integralmente do fenômeno jurídico. Nessa leitura jurídica tradicional, o Direito é uma totalidade pensada e sistematizada num ordenamento ideal, este estratificado a partir da lógica do pressuposto constitucional fundamental.

Assim, é perfeitamente inteligível o tamanho impacto que a Constituição Federal de 1988 tenha causado no mundo da pesquisa jurídica, pois a nova ordem transcendental, fonte de validade normativa, precisava ser mais bem contemporizada. De fato, a análise da temática das 70 teses revelou a maior incidência, no período, de títulos referentes ao Direito Constitucional, evidenciando a importância contextual da Constituição de 1988 para a expansão e para a consolidação da pesquisa em Direito.

Mesmo quando o problema de pesquisa é comum a outras áreas do conhecimento jurídico, a constitucionalidade o permeia, quer diretamente, quer indiretamente. Tanto no Direito Privado quanto no Direito Público vai sendo consolidada a nova coerência legislativa derivada da hermenêutica constitucional democrática estabelecida. Os temas de Direito Constitucional (ou a eles pertinentes) dimensionam parte do impacto positivo do texto constitucional de 1988. Em números, totalizam 49 textos, o que significa $71 \%$ da amostra pesquisada ${ }^{4}$.

Esses mesmos números sugerem uma colaboração bastante expressiva do texto da "Constituição Cidadã" de 1988 para o amadurecimento da atividade acadêmica nacional e para a própria consolidação do texto constitucional brasileiro. Também sugerem que a atividade acadêmica e a consolidação do texto constitucional sejam fenômenos em íntima correlação, uma vez que muitos desses textos foram publicados em livros e adotados como parâmetro de julgamento no Poder Judiciário brasileiro.

Os temas relativos às questões profissionais pragmáticas e sem referência direta à hermenêutica constitucional totalizam o número de 12 teses, representando $17 \%$ da preferência dos doutores titulados entre 2000 a 2010. Enquanto temas ligados à Teoria do Direito e à Filosofia do Direito foram contemplados em quatro teses cada, significando $6 \%$ das preocupações dos doutorandos no período. A legitimidade do texto constitucional veio não pela via política tradicional, senão pelo do protagonismo político do Supremo Tribunal Federal, que colocou o discurso jurídico em evidência nacional.

Segundo Atienza (2006), a argumentação jurídica, no campo teórico, possui três planos diferentes: a produção de normas jurídicas, a aplicação das normas positivadas a casos

\footnotetext{
${ }^{4}$ Durante a maior parte desta seção do texto preferiu-se, por questão ética, não identificar as teses, para não expor indevidamente os programas de pós-graduação estudados. Coerente aos limites desta pesquisa, cujas hipóteses aguardam aprofundamento posterior.
} 
Volpato / Metodologia da pesquisa versus pesquisa da metodologia: interfaces da dogmática jurídica na pósgraduação

concretos e o antecessor da dogmática jurídica. A mais complexa e tipicamente jurídica é a dogmática, cuja função é fornecer critérios para a produção do Direito e oferecer critérios hermenêuticos de sua aplicação, além de ordenar e de ajudar na sistematização do ordenamento jurídico. Isto é, enquanto os aplicadores do Direito resolvem casos concretos, os estudiosos da dogmática do Direito se ocupam de casos abstratos, ainda que tal divisão seja na realidade bastante relativa.

No mundo jurídico, existem dois contextos diferenciados, de um lado a justificação, centrado na opinião do jurista que decide sobre o caso concreto, cuja análise lógica não seria suscetível; e, doutro lado, o contexto de descoberta, que se utiliza de métodos científicos de validação teórica. O atual Estado Democrático de Direito resultante do contrato social potencializa duas posições diferentes do jurista estudioso, conforme o método e a utilidade buscada à ordem política e ao Estado. Essas duas posições privilegiam, em parte, a vontade (a decisão e a justificação) e, por outro lado, a razão (a descoberta purificada do Direito).

Marshall, em fins da década de 1930, quando analisa o campo da ação política do Direito, de modo bastante preciso, descreve o mecanismo de atuação do mundo jurídico, destacando as nuances políticas e econômicas envolvidas:

\footnotetext{
O direito tem o propósito de estabelecer e defender o soberano - o que significa estabelecer e defender os interesses econômicos e as ideologias das forças políticas das quais o soberano depende ou das que, através de pura força física e poder econômico que possa reunir, incluem em si o poder soberano. $\mathrm{O}$ direito, de modo geral, não pode ser irresponsável, pois, se for arma útil da soberania, deve ser orientado no sentido de alcançar unidade, isto é, ausência das condições desintegradoras, nas quais um competidor pode encontrar apoio. Por isso, os sistemas jurídicos tendem ao que Laski denomina "a beatificação da ordem”. (MARSHALL, 2008, p. 55).
}

Se a matriz de "poder absoluto" exigia um direito absoluto no passado, a realidade contemporânea democrática precisa de uma matriz plural (consensual) para dar sustentabilidade ao Direito. É nessa fissura epistemológica que o novo realismo jurídico se estabelece e se aprofunda (HESPANHA, 2013, p. 61-62).

As indagações "jusfilosóficas" nacionais ainda se centram no pensamento europeu e, mais raramente, enfrentam o realismo jurídico norte-americano ${ }^{5}$. A novidade, estimulada por essas reflexões jurídicas norte-americanas, não gera no Brasil maiores frutos. A tradição brasileira ainda não processou intelectualmente as críticas dos realistas ao formalismo positivista. Por isso, a crise teórica nacional, segundo esse viés, pode ser diagnosticada como uma hesitação na transição do formalismo de feição positivista para o neoformalismo "pretensamente crítico"; porém, insuficiente para transcender a renovada dogmática de teorias

\footnotetext{
${ }^{5}$ As variantes teóricas do realismo e do pós-realismo jurídico ainda permanecem pouco conhecidas, sem conseguir despertar um interesse substantivo aos pesquisadores do Direito no Brasil, ainda tradicionalmente educados conforme o legado europeu continental (GODOY, 2013).
} 
Volpato / Metodologia da pesquisa versus pesquisa da metodologia: interfaces da dogmática jurídica na pósgraduação

sistêmicas, fortalecidas pelos neocontratualistas que a elas conjugaram a teoria da razão comunicativa.

$\mathrm{Na}$ verdade, esses são "[...] pilares de discurso vazio, agente de neokantismo que não se tem coragem de abandonar” (GODOY, 2013, p. 6). Os modelos de dedução lógica do realismo jurídico, cuja reflexão é um mecanismo para resolver problemas concretos, rompem com a metafísica em favor do pragmatismo e do conhecimento empírico, constituem postura de estudo com potência para oxigenar a teoria jurídica brasileira. Ocorre que o atraso nacional permanece, para além da tradição pedagógica, pela escassa literatura estrangeira traduzida ao português. A maioria dos juristas brasileiros não consulta obras estrangeiras em seu idioma original, desprezando curiosamente essa fonte primária de saber.

\section{A OPÇÃO METODOLÓGICA DAS PESQUISAS CONSULTADAS}

A leitura das teses seguiu um plano prévio de processamento dos dados. Nesse plano, a questão metodológica, afinada à coerência temática, foi absolutamente indispensável. Os textos selecionados foram catalogados em fichas individuais, cujas anotações significativas facilitaram constatações a serem mais bem refletidas. O resumo, por exemplo, demonstrou-se uma importante fonte de informação quanto às temáticas e às metodologias, ainda que em pelo menos quatro teses, de diferentes programas estudados, não se encontre um texto de resumo.

Por meio dos textos selecionados, constataram-se preocupações com determinadas escolhas metodológicas e com a justificação de métodos específicos para enfrentamento do problema de pesquisa, pois simplesmente não são expressas (não compõem o texto).

Os pesquisadores preferem manter silêncio de suas bases metodológicas de trabalho, colocando em risco a "cientificidade" de seus esforços. O apuro metodológico é o fator que controla a subjetividade do pesquisador na observação científica. Sem ela, o que se produz é ideologia e não ciência propriamente dita.

Essa curiosa omissão sobre a metodologia se repete nas introduções das teses em quase todos os trabalhos (duas teses não apresentam um texto introdutório propriamente dito). Se 74\% dos resumos não falam sobre método ou sobre metodologia, na introdução, dentre eles $51 \%$ não indicam o modo de construção da pesquisa e do relatório, sendo significativo o posicionamento de $4 \%$ das teses, que se manifestaram expressamente "contrárias" às questões de método.

É significativo o ponto de partida das nuances metodológicas e substanciais agora identificadas. Acreditava-se que o seu melhor desvendar facilitaria o diagnóstico da problemática e, quem sabe, abriria espaço para um novo vislumbrar de futuras perspectivas de evolução da pesquisa em Direito. Seriam perspectivas talvez mais capazes de suplantar as conhecidas críticas de atraso, de isolamento do jurídico em relação aos demais saberes científicos ou, ainda, configurar-se-iam como um modo peculiar de superação da confusão entre prática profissional e pesquisa acadêmica (ADEODATO, 1999; FRAGALE FILHO; VERONESE, 2004; NOBRE, 2005). Por isso o desejo de cotejar os principais métodos, ainda que não expressamente declarados, a partir das características predominantes dos relatórios lidos. 
Volpato / Metodologia da pesquisa versus pesquisa da metodologia: interfaces da dogmática jurídica na pósgraduação

De modo não tão surpreendente, constatou-se, nessa abordagem empírica, que as pesquisas em nível de doutoramento no Brasil são, em sua esmagadora maioria, bibliográficas ou bibliográfico-documentais. Seria ideal conseguir precisar melhor a natureza e o peso das fontes utilizadas, se documentais primárias ou secundárias.

Porém, como pode acontecer (com certa frequência), o autor se propõe a algo e faz outro. Uma análise séria das fontes de pesquisa, especialmente em matéria de história do Direito, por exemplo, seria condigna a uma inédita tese de doutoramento por completo. Ainda que central a questão, de relevância ímpar para a qualidade de um estudo com pretensões científicas, não se pode neste estudo, altamente limitado por seu objeto (amostra), solver por completo o enigma.

Preferiu-se indicar com menor rigor a expressão estudo "bibliográfico-documental", que em termos técnicos mais apurados são métodos diferentes e independentes, curiosamente coadjuvantes frequentes na pesquisa jurídica. Seguindo uma avaliação percentual, que parece pertinente, verifica-se que as metodologias de cunho bibliográfico, se somadas, totalizam $76 \%$ dos estudos. Contrapondo-se a $9 \%$ de pesquisas interdisciplinares, $13 \%$ de análises fenomenológicas (em sua quase maioria, de cunho sistêmico) e do modesto $1 \%$ de pesquisa de campo e dialética.

\section{Gráfico 2 - Metodologia adotada}

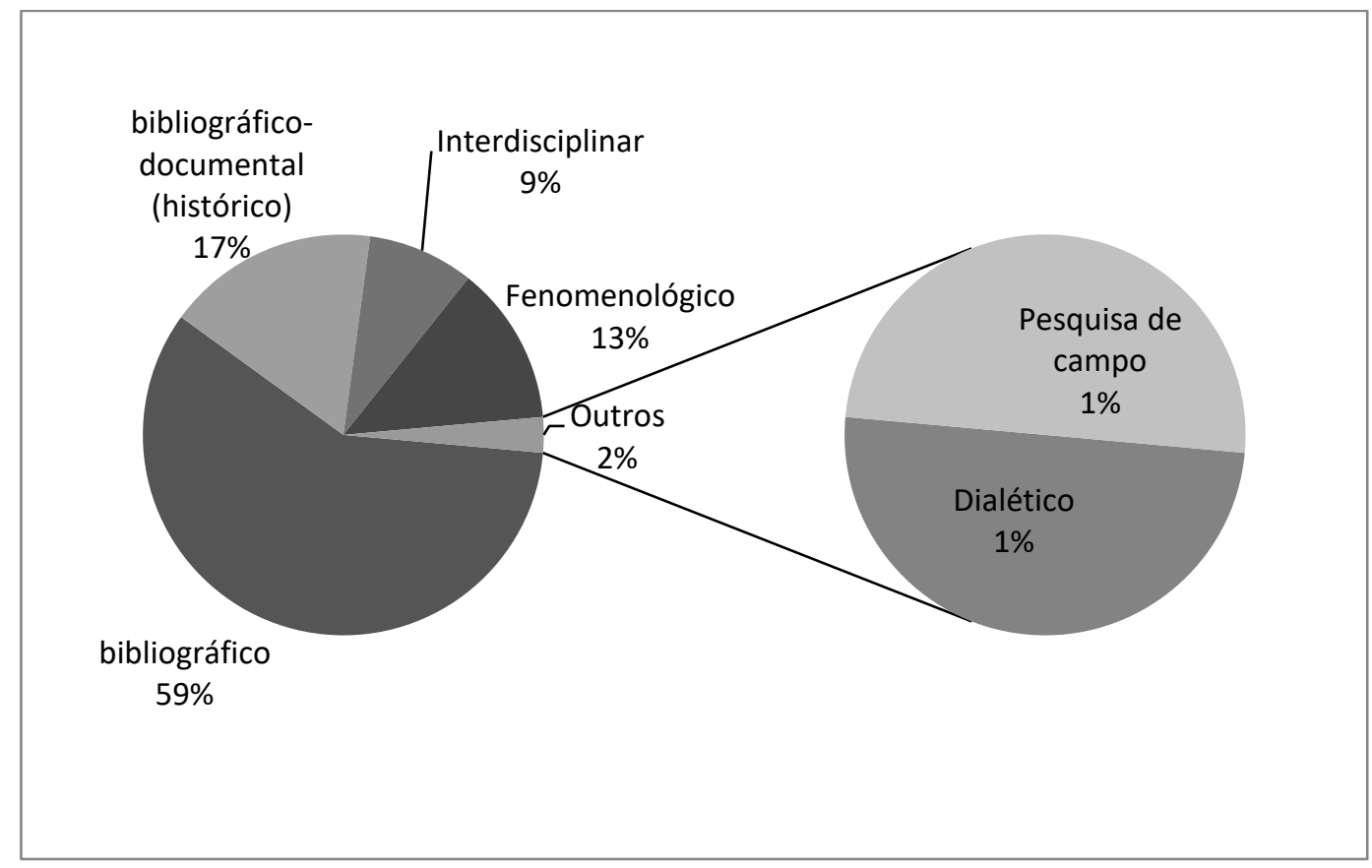

Fonte: Elaboração própria a partir das teses selecionadas.

Aprofundando o foco no procedimento de pesquisa que optaram por levantamento bibliográfico foi possível identificar o perfil do material consultado. Os livros, nacionais e internacionais, são fontes de pesquisa primordial, nesse formato. Artigos científicos e dados disponíveis na internet são bem menos utilizados em comparação a levantamentos 
Volpato / Metodologia da pesquisa versus pesquisa da metodologia: interfaces da dogmática jurídica na pósgraduação

jurisprudenciais e legislativos. Quantitativamente, os livros nacionais consultados nas teses, em sua maioria, referenciaram de 51 a 100 obras.

\section{Gráfico 3 - Quantitativo de livros referenciados nas teses}

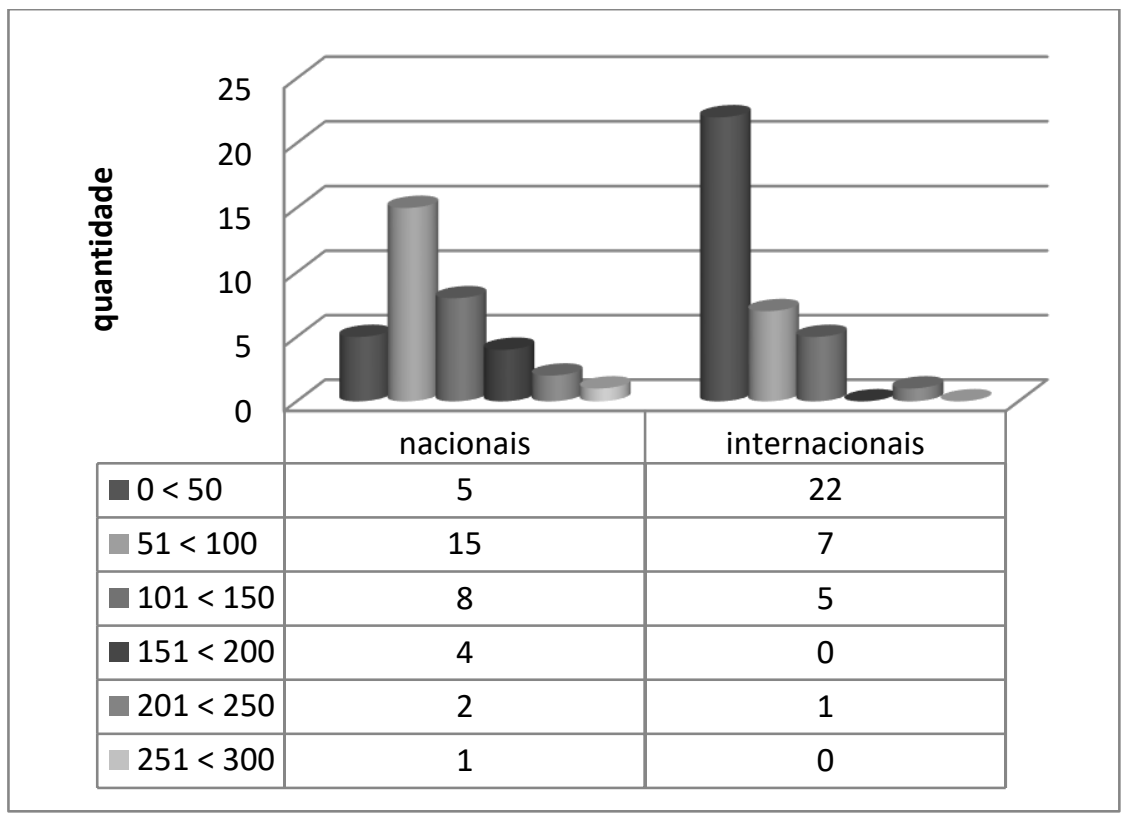

Fonte: Elaboração própria a partir das teses selecionadas.

Observou-se a composição do primeiro segmento da tabela (entre 0 a 50), que corresponde à utilização de obras em idioma estrangeiro, o espanhol e italiano predominam, o inglês é utilizado em segmentos temáticos pontuais. Os artigos científicos, quantitativamente considerados, representam, na maioria, se nacionais, a cifra de cinco a 15 referências bibliográficas, mas, se colocar em foco artigos internacionais, a maioria das teses lidas buscou esse tipo de fonte bibliográfica, conforme o Gráfico 4: 
Volpato / Metodologia da pesquisa versus pesquisa da metodologia: interfaces da dogmática jurídica na pósgraduação

\section{Gráfico 4 - Quantitativo de referências nacionais e internacionais}

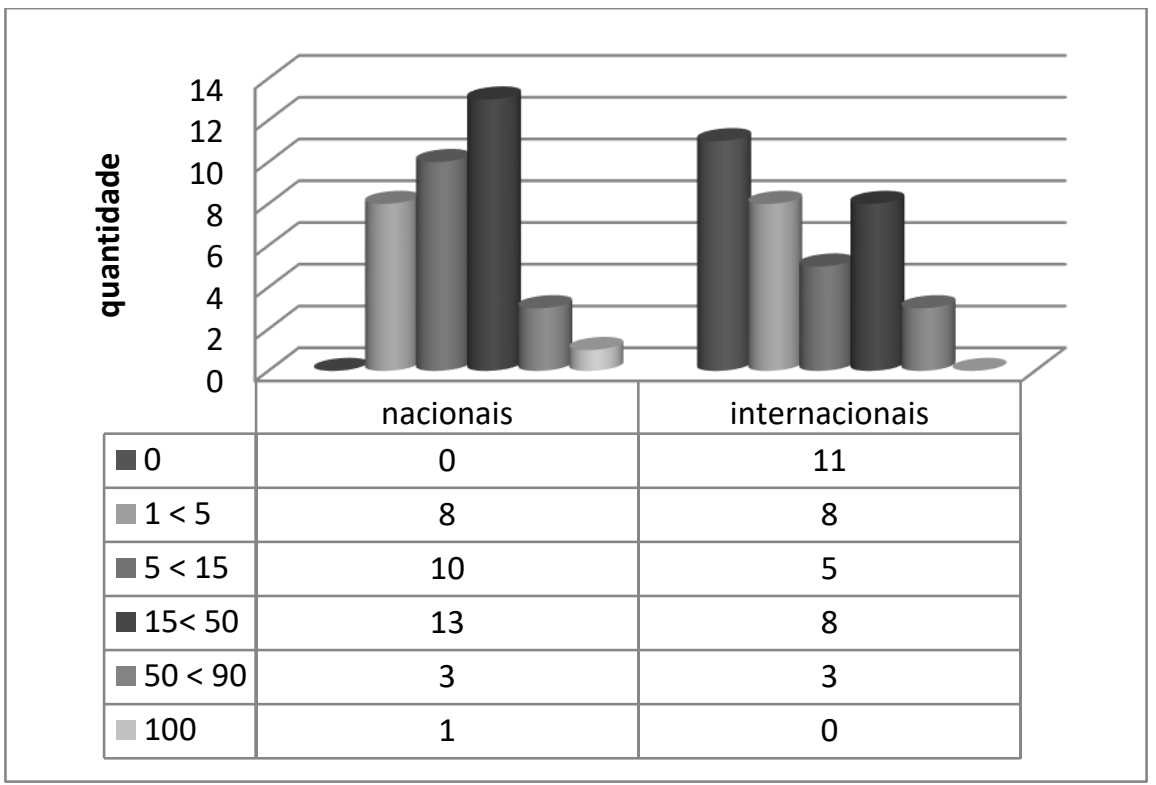

Fonte: Elaboração própria a partir das teses selecionadas.

A busca pelo perfil metodológico mais comum em cada instituição revela traços característicos bastante específicos de cada uma das oito instituições pesquisadas. Por isso, para dar maior visibilidade às constatações alcançadas no Gráfico 5, inscrevem-se as metodologias verificadas em cada um dos programas de doutorado consultados.

\section{Gráfico 5 - Metodologia por programas de pós-graduação}

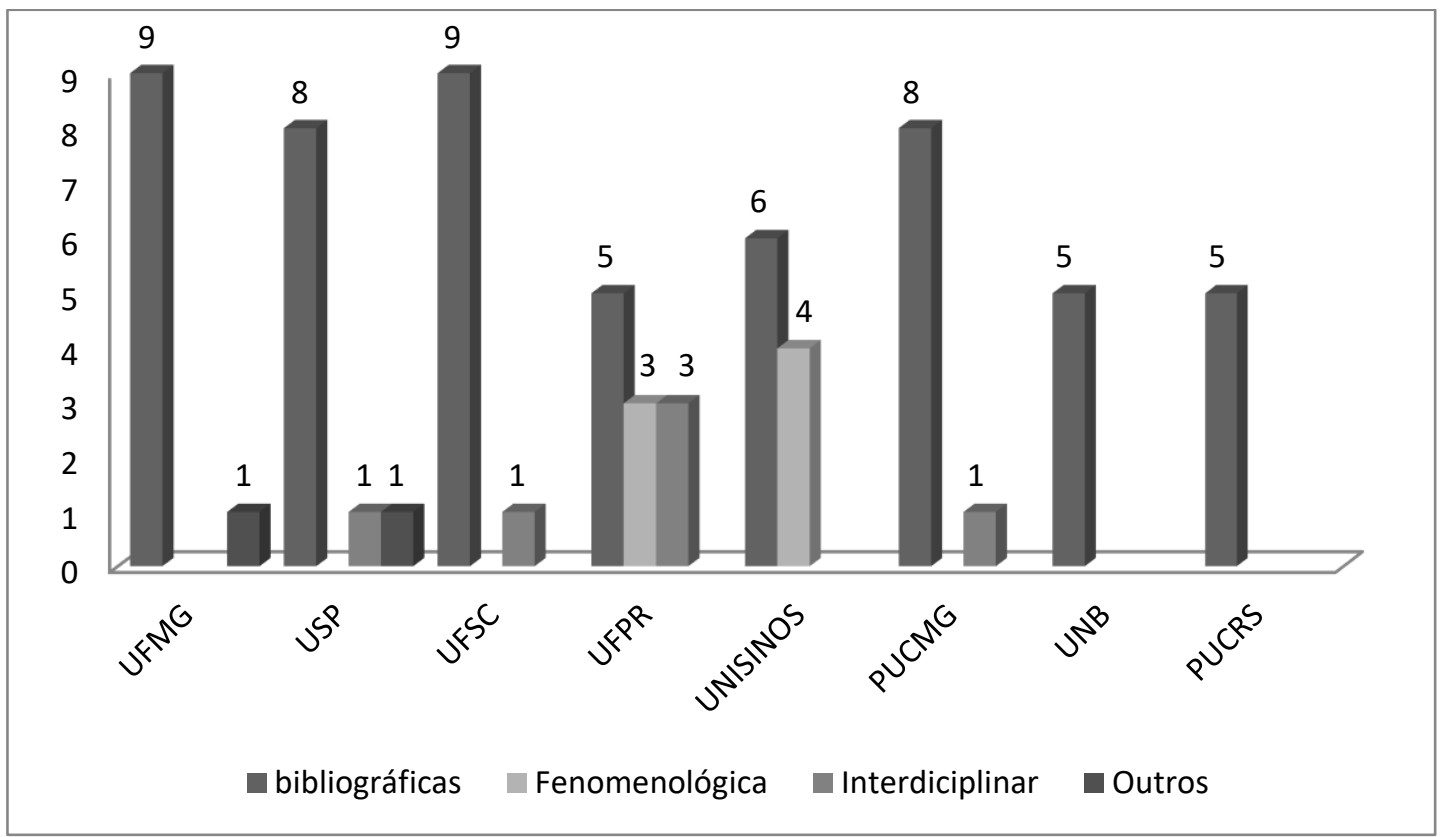

Fonte: Elaboração própria a partir das teses selecionadas. 
Volpato / Metodologia da pesquisa versus pesquisa da metodologia: interfaces da dogmática jurídica na pósgraduação

Além das nuances constitucionais, o recorte histórico é uma quase constante do discurso, considerado como recurso metodológico, podendo até, de modo bastante sugestivo, acreditar em um enredo típico para as pesquisas jurídicas. O panorama histórico descrito evidencia a estratégia metodológica típica do argumento de autoridade, conforme detectado no conteúdo das teses estudadas, numa leitura dirigida. O que não implica afirmar que efetuada uma avaliação de seu enredo, não se possa constatar que tais textos deixem de valorizar a história como fonte de conhecimento real do Direito em diferentes épocas, conforme o olhar de um jurista e não de um pesquisador da área.

Parece existir uma "jurisprudência secreta”, uma prática não expressa, mas poderosamente vinculante do saber Direito "direito". Por isso, com as devidas simplificações dignas de toda classificação, o estudo do enredo (da construção do relatório, conforme o sumário) pode ser sintetizado em três tipos característicos de formatos, sendo: evolucionista, constitucionalista e sistêmico.

O enredo mais comum foi classificado como evolucionista. Nele, o fator predominante é o elemento histórico, em que é construído um cenário com "atores principais", com algumas poucas variantes referentes à evolução do Estado e do Direito, sugerindo certa simetria entre a estrutura estatal e o aparato jurídico. Das teses lidas, com acréscimos de ordem constitucional e de cunho da "nova hermenêutica", 37 das 70 teses seguem esse formato.

O segundo modelo, batizado de constitucionalista, toma como ponto de partida o texto da Constituição Federal (sobretudo, o de 1988), para depois recorrer a uma recuperação histórica dirigida a demonstrar a evolução da tutela jurídica segundo as diferentes conformações do Estado de Direito capitalista e contemporâneo. Esse modelo alcançou a expressiva marca de 17 textos com essa estrutura.

O terceiro segmento adota como critério primordial o enfoque sistêmico, sendo considerado, para fins deste estudo, como epistêmico, e alcançou o número expressivo de 15 teses.

A história, nas teses em Direito, chancela um discurso de autoridade, como se o fator histórico fosse coadjuvante do fato: o fenômeno jurídico evolui no tempo e espaço. Como a internacionalização, a globalização e os impactos do tempo presente são violentos a esta "estática" do conhecimento jurídico pesquisado. As teses refletem sensivelmente essa reação, sendo significativo o deslocamento do foco da antiguidade para o pós-moderno, conforme o Gráfico 6: 
Volpato / Metodologia da pesquisa versus pesquisa da metodologia: interfaces da dogmática jurídica na pósgraduação

\section{Gráfico 6 - Evolução do foco do fenômeno jurídico}

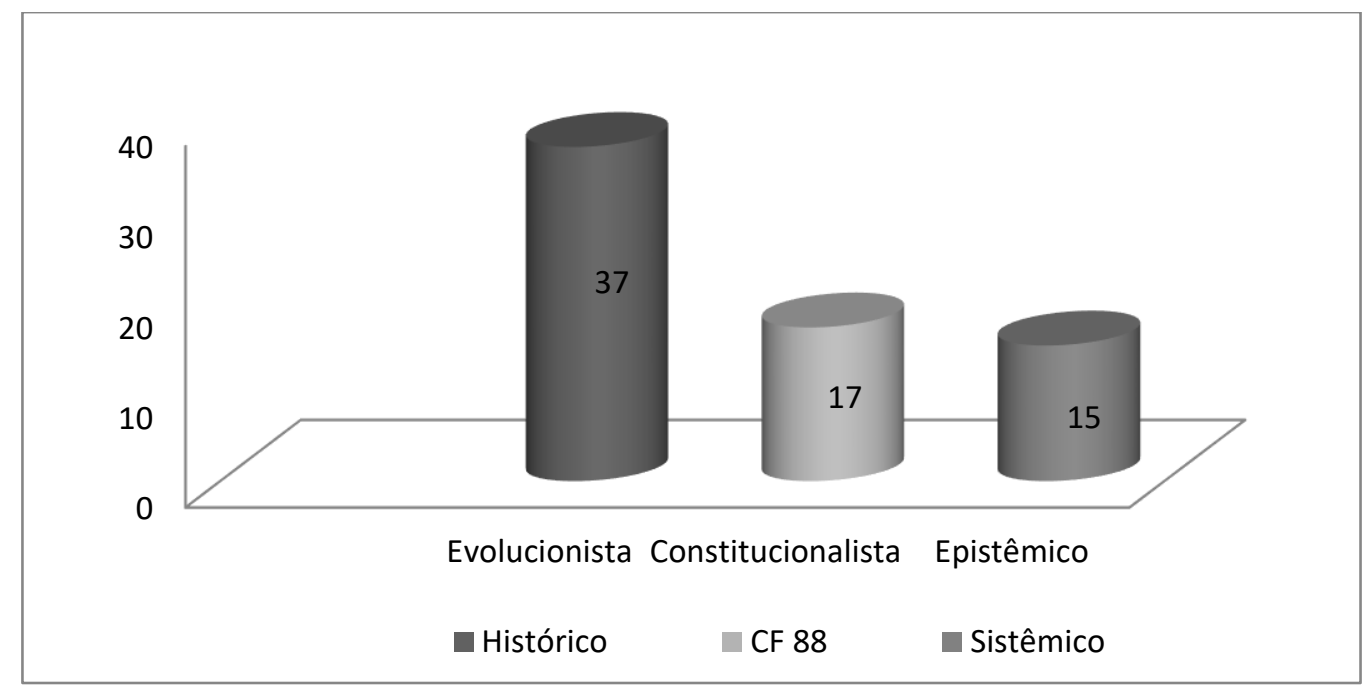

Fonte: Elaboração própria a partir das teses selecionadas.

O aparente descaso com a questão metodológica deixa mais um traço característico curioso nas teses consultadas, o sumário demonstra que no desenvolvimento do texto coexistem desequilíbrios de ideias ou de argumentos, na medida em que, num mesmo relatório há capítulos de três páginas, e outros com mais de uma centena de páginas.

Nas introduções das teses, os seus autores indicam, de modo quase unânime, o tema (problema), a relevância social do estudo - muitas vezes com enfoques pragmáticos evidentes -, salientando objetivos bastante claros. Ocorre, porém, que menos de dez delas apresentam, de modo coerente, suas hipóteses de pesquisa, dessa forma prejudicando a coerência científica do trabalho e a conclusão (os resultados do estudo).

As conclusões das teses, quando existem, são redigidas na forma de parecer técnicojurídico, como se fosse possível legitimar a coerência elencada no trabalho. As "conclusõesparecer" ocorrem em oito teses, sendo que em outras quatro o texto de considerações finais simplesmente não existe. A leitura dos textos remanescentes demonstrou que os pesquisadores concluíram bem seus trabalhos, porém, a grande maioria, independentemente do método ou do conjunto de métodos utilizado, não indica novos temas a serem pesquisados futuramente.

A questão metodológica, tão importante a outras áreas de conhecimento, em vista das especificidades da construção do saber jurídico, na área jurídica, é agravada pela falta de canais de comunicação entre as instâncias acadêmicas e as judiciárias. A timidez das pesquisas do Direito aponta para a necessidade de criar espaços apropriados para a discussão acadêmica, em que a comunidade científica possa estabelecer uma interlocução, inclusive com outras áreas, na qual a crítica e a troca de saberes permanente aprimorem qualitativamente o conhecimento jurídico.

A presente análise de frequência de tais quesitos, seguindo a configuração metodológica típica, não é completa para precisar o panorama complexo da pesquisa e do horizonte do pesquisador. Porém, deseja ser substancialmente acadêmica ao enfrentar algumas armadilhas 
Volpato / Metodologia da pesquisa versus pesquisa da metodologia: interfaces da dogmática jurídica na pósgraduação

teóricas, metodológicas e institucionais, que fragilizam a produção de conhecimento científico em Direito.

\section{A EFICIÊNCIA DOS PROGRAMAS DA AMOSTRA}

A questão da pesquisa jurídica nacional, sob o enfoque realístico, encontra um panorama pitoresco: a pesquisa é realizada por profissionais de Direito que não são profissionais da pesquisa. A excessiva carga horária em sala de aula, os baixos salários, a atribulada conciliação de horários entre escritórios e repartições são critérios muito mais significativos para aferir a qualidade institucional, superiores à mera quantidade de artigos ou livros publicados. Os mais diferentes profissionais - da magistratura, do ministério público, da advocacia e de outras carreiras jurídicas (como delegados de polícia) - combinam o tempo do curso de doutorado com suas atividades profissionais.

Mais delicado é, portanto, o impacto do fator tempo no processo de doutoramento. Se ele estiver sobrecarregado de formalidades, de relatórios, de aulas expositivas, de modo que os pesquisadores (alunos e professores) ultrapassem dez horas trabalhando, fatalmente o resultado, ou a pesquisa, tem mais chances de não ser um primor de qualidade.

O ser humano, para ser produtivo (criativo), precisa dispor de tempo para si. Os programas brasileiros, estimulados pela Capes, deveriam trabalhar na reeducação para o tempo livre. Por isso, pareceu conveniente e oportuno realizar o cotejo dos dados catalogados de modo a traçar o perfil dos 70 pesquisadores da amostra selecionada.

As proporções encontradas demonstram que $62 \%$ são profissionais pesquisadores que dividem suas atividades acadêmicas ou com cargos públicos, ou com escritórios particulares. Dos professores que se dedicam à docência, constatou-se que $21 \%$ exercem atividades em mais de uma instituição. Apenas $11 \%$ podem ser considerados pesquisadores profissionais, com vínculos de exclusividade e projetos de pesquisa estáveis. Outros $6 \%$ dos doutores sequer possuem Currículo Lattes cadastrado ${ }^{6}$.

Após tal constatação, passou-se a mensurar a produção acadêmica dos doutores selecionados na amostra. Foi demonstrado que a UnB possui a maior quantidade de artigos publicados, com a média matemática de 5,4 entre seus doutorados. A menor média foi da UFPR, na razão de 2,1 artigos publicados. Considerando-se a quantidade de livros publicados, a instituição cujos alunos mais publicaram foi a UnB, com média de 2,6 livros por aluno. O menor número de livros publicados foi da Unisinos, com 0,4 livros por aluno.

Os capítulos de livros foram contabilizados separadamente e, mais uma vez, o programa de pós-graduação que mais colaborou com capítulos de livros publicados foi a UnB, com 2,6

\footnotetext{
${ }^{6}$ Das teses selecionadas não possuem currículo Lattes: dois doutores da USP, um doutor da UFSC e outro da UFMG. Em número inteiro seriam quatro e em percentual o valor de 6\% (seis por cento).
} 
Volpato / Metodologia da pesquisa versus pesquisa da metodologia: interfaces da dogmática jurídica na pósgraduação

textos por doutor. A menor foi alcançada pela UFMG, com 0,6 capítulos por pessoa, com os seguintes coeficientes:

\section{Tabela 1 - Produção por Programa}

\begin{tabular}{|c|c|c|c|}
\hline Programa & Artigos & Livros & Capítulos de livros \\
\hline UFMG & 4 & 1,5 & 0,6 \\
\hline USP & 2,8 & 2,2 & 2,7 \\
\hline UFSC & 4 & 1,5 & 2,1 \\
\hline UFPR & 2,1 & 1,8 & 1,5 \\
\hline Unisinos & 3,6 & 0,4 & 1,5 \\
\hline PUC Minas & 5,2 & 0,7 & 1,5 \\
\hline UnB & 5,4 & 2,6 & 2,6 \\
\hline PUCRS & 3 & 1,7 & 1,5 \\
\hline
\end{tabular}

Fonte: Elaboração própria a partir de dados da Plataforma Lattes.

Na Tabela 1 constam todos os valores apurados, com base nos dados informados no currículo Lattes dos 70 doutores selecionados. E induzem a uma questão interessante: qual programa seria o mais eficiente? Em termos simplórios, poder-se-ia defender que os melhores índices de qualidade são dos programas que apresentam a maior grandeza matemática apurada. Porém, esta interpretação não é a mais acertada.

O doutoramento é espaço para gerar maturidade acadêmica, assim sendo, os mais eficientes são os programas que melhor equilibraram o uso dos recursos disponíveis para vazão de seu saber - aqueles para os quais, de modo ótimo, aproximaram-se do coeficiente mínimo exigido pela Capes, ou seja, duas publicações. Visto por este prisma, a UFPR tem o programa mais eficiente, enquanto a UnB é a menos eficiente.

Outro indicador importante de eficiência é o tempo médio de titulação observado na relação de doutores constante na amostra selecionada, sintetizado no Gráfico 7. Nota-se que o tempo médio de titulação dos doutores foi de 3,1 anos, para a PUC Minas, com o menor tempo, até os 4,4 anos da UFSC, com o pior índice de aproveitamento, segundo essa variável. Importa salientar que muitas teses foram concluídas em seis e até em oito anos, por isso, o Gráfico 7 foi realizado a partir da média aritmética de cada instituição. 
Volpato / Metodologia da pesquisa versus pesquisa da metodologia: interfaces da dogmática jurídica na pósgraduação

\section{Gráfico 7 - Tempo médio de qualificação dos autores das teses}

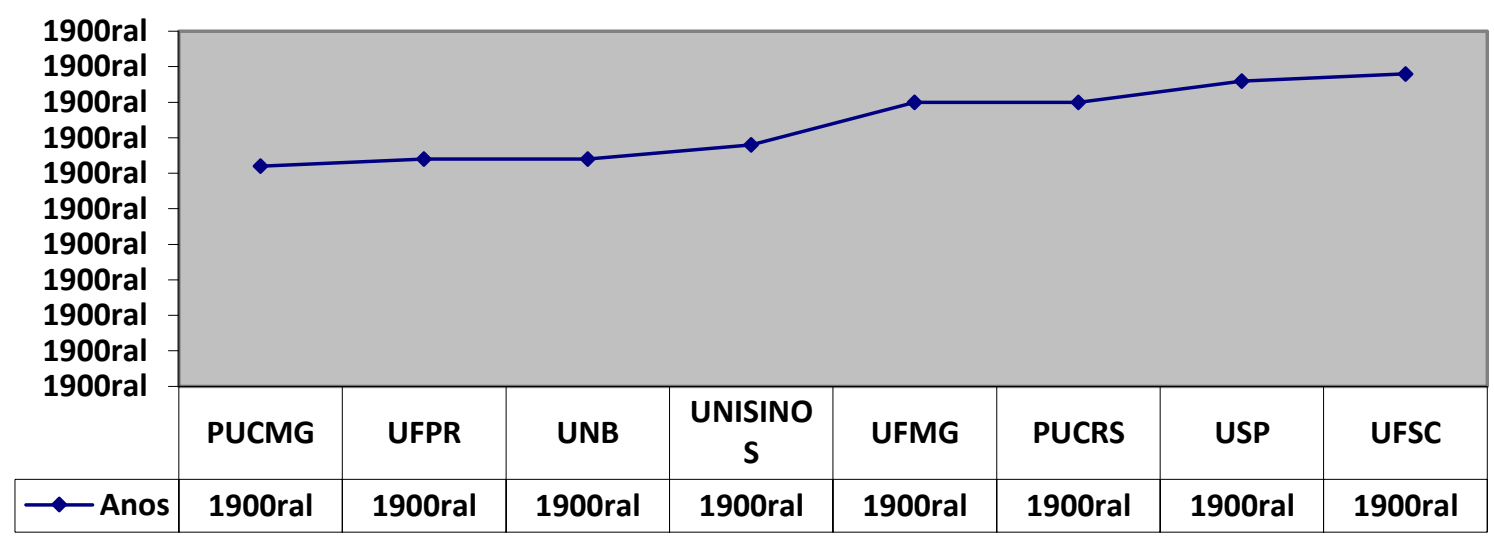

Fonte: Elaboração própria a partir de dados da Plataforma Lattes.

Deste modo, trabalhar com a interpretação de dados quantitativos não é processo de simples leitura linear. Requer, das instituições envolvidas, em especial dos órgãos a quem compete a avaliação da pós-graduação, sensibilidade e bom senso, além de conhecimentos mínimos de gestão de projetos, política, matemática e estatística.

A Plataforma Sucupira, em implantação no período da coleta de dados, possibilitou a comparação quantitativa da eficiência dos programas de doutorado estudados, de forma bastante ágil, em outro aspecto, com base em informações cadastradas no período de 2010 a 2014. Embora o período não seja o exatamente estudado, num primeiro momento do bojo de análise deste artigo, considerou-se uma empreitada necessária como material de análise a complementar o conteúdo das teses lidas, de modo a compreender o impacto real das opções políticas da gestão dos programas avaliados.

O presente estudo se configurou em uma análise de regressão linear. Uma verificação de natureza estatística com o objetivo de constatar a relação funcional entre uma variável dependente (a pesquisa científica em Direito no doutorado) com duas variáveis independentes (a política científica da área do Direito e os regimentos internos de cada programa, a partir da assunção do sistema trienal de avaliação).

Para instrumentalizar esta análise quanti-qualitativa se examinou liminarmente os regimentos internos dos programas de pós-graduação avaliados. É uma análise interessante e que merece ser apresentada de modo pormenorizado, em separado. Porém, dela se pode concluir que, a partir do final da década de 1990, existe um alinhamento das dinâmicas institucionais dos programas de pós-graduação em Direito, priorizando o regramento detalhado do fluxo discente. No presente artigo, deseja-se avaliar a eficiência desta escolha política e seus efeitos práticos diretos nas teses lidas.

Apesar de suscitar certa dificuldade pela ausência de domínio da matemática e da estatística, o preceito é dotado de grande simplicidade lógica: uma reta é composta, no mínimo, 
Volpato / Metodologia da pesquisa versus pesquisa da metodologia: interfaces da dogmática jurídica na pósgraduação

por dois pontos. Assim, fixo o padrão da pesquisa, se pode traçar, em meio às dinâmicas institucionais burocráticas e artesanais, um direcionamento político e institucional peculiar.

O tipo burocrático é marcado pela disciplina, pelo controle e institucionalizado dos pesquisadores (docentes e discentes). Seu objetivo primeiro, que imprime característica fundamental para esta dinâmica, é cultivar certos padrões de produção criteriosamente definidos pela instituição, conforme linhas e grupos de pesquisa internos do seu programa de pósgraduação, por exemplo (VOLPATO, 2015).

O tipo artesanal tem por prioridade buscar a originalidade, por isso, a transmissão de conhecimento e de habilidades é permeada por "[...] elevado grau de autoconfiança e espírito crítico[...]" (VOLPATO, 2015, p. 103) dos envolvidos: a instituição que não possui mecanismos de controle particularizado do ritmo de trabalho. Os docentes mantêm uma relação de controle pessoal mais estreito no decorrer do cumprimento das disciplinas, enquanto a relação "orientador-orientando", por exemplo, tende a ser dotada por acentuado grau de liberdade.

Um retrato perceptível a partir do resultado das pesquisas de doutoramento produzidas e condizente a sua matriz temporal e da cultura institucional e histórica, da academia na qual foi formulada, optou-se por avançar em uma análise de correlação. Por isso, nela se optou por trabalhar com textos supervenientes ao período de 2000-2010, não para apenas registrar um traço histórico, mas para verificar a existência de uma fenomenologia mais ampla e complexa.

$\mathrm{Na}$ verdade, pode-se verificar que os pressupostos de excelência e de eficiência institucional se traduzem em cifras concretas. Números que merecem ser conhecidos e, coerentemente, interpretados. Para demonstrar graficamente, pode-se formular um gráfico integrado que divide anualmente os seguintes dados: alunos já matriculados, os novos (ingressantes), os titulados, os desligados, bem como aqueles que abandonaram o programa, apurando matematicamente a eficiência do resultado de cada um dos programas pesquisados.

Tabela 2 - Fluxo discente no doutorado em Direito 2010-2014

\begin{tabular}{|c|c|c|c|c|c|c|}
\hline & $\begin{array}{c}\text { Alunos } \\
\text { matriculados }\end{array}$ & $\begin{array}{l}\text { Novos } \\
\text { alunos }\end{array}$ & Titulados & Desligados & Abandono & Resultado \\
\hline \multicolumn{7}{|c|}{2010} \\
\hline UFMG & 22 & 18 & 0 & 0 & 0 & 40 \\
\hline UFPR & 15 & 25 & 1 & 0 & 0 & 39 \\
\hline UFSC & 32 & 0 & 5 & 0 & 0 & 27 \\
\hline USP & 43 & 118 & 0 & 1 & 0 & 160 \\
\hline Unisinos & 13 & 9 & 0 & 0 & 0 & 22 \\
\hline UnB & 11 & 11 & 0 & 0 & 0 & 22 \\
\hline $\begin{array}{c}\text { PUC } \\
\text { Minas }\end{array}$ & 16 & 29 & 0 & 0 & 0 & 45 \\
\hline PUCRS & 4 & 9 & 0 & 0 & 0 & 13 \\
\hline \multicolumn{7}{|c|}{2011} \\
\hline UFMG & 40 & 17 & 0 & 0 & 0 & 57 \\
\hline UFPR & 39 & 14 & 2 & 0 & 0 & 51 \\
\hline UFSC & 27 & 9 & 9 & 0 & 0 & 27 \\
\hline USP & 160 & 121 & 2 & 4 & 0 & 275 \\
\hline Unisinos & 22 & 10 & 2 & 0 & 0 & 30 \\
\hline
\end{tabular}


Volpato / Metodologia da pesquisa versus pesquisa da metodologia: interfaces da dogmática jurídica na pósgraduação

\begin{tabular}{|c|c|c|c|c|c|c|}
\hline UnB & 22 & 12 & 2 & 0 & 0 & 32 \\
\hline $\begin{array}{l}\text { PUC } \\
\text { Minas }\end{array}$ & 45 & \multicolumn{4}{|c|}{ Minas } & 74 \\
\hline PUCRS & 13 & 6 & 0 & 0 & 0 & 19 \\
\hline \multicolumn{7}{|c|}{2012} \\
\hline UFMG & 57 & 13 & 0 & 1 & 0 & 69 \\
\hline UFPR & 51 & 30 & 1 & 4 & 0 & 76 \\
\hline UFSC & 27 & 28 & 6 & 0 & 0 & 49 \\
\hline USP & 275 & 122 & 5 & 19 & 0 & 373 \\
\hline Unisinos & 30 & 12 & 5 & 0 & 0 & 37 \\
\hline UnB & 32 & 19 & 0 & 0 & 0 & 51 \\
\hline $\begin{array}{c}\text { PUC } \\
\text { Minas }\end{array}$ & 74 & 31 & 4 & 1 & 0 & 100 \\
\hline PUCRS & 19 & 13 & 0 & 2 & 0 & 30 \\
\hline \multicolumn{7}{|c|}{2013} \\
\hline UFMG & 69 & 27 & 21 & 0 & 0 & 75 \\
\hline UFPR & 76 & 18 & 11 & 0 & 0 & 83 \\
\hline UFSC & 49 & 28 & 9 & 1 & 0 & 67 \\
\hline USP & 373 & 116 & 99 & 9 & 0 & 381 \\
\hline Unisinos & 37 & 20 & 10 & 0 & 0 & 47 \\
\hline UnB & 51 & 19 & 7 & 0 & 0 & 63 \\
\hline $\begin{array}{c}\text { PUC } \\
\text { Minas }\end{array}$ & 100 & 42 & 21 & 3 & 0 & 118 \\
\hline PUCRS & 30 & 13 & 8 & 0 & 0 & 35 \\
\hline \multicolumn{7}{|c|}{2014} \\
\hline UFMG & 75 & 39 & 15 & 0 & 0 & 99 \\
\hline UFPR & 83 & 16 & 13 & 0 & 0 & 86 \\
\hline UFSC & 67 & 19 & 7 & 0 & 0 & $\begin{array}{l}7 \\
9\end{array}$ \\
\hline USP & 381 & 130 & 102 & 14 & 0 & 395 \\
\hline Unisinos & 47 & 18 & 9 & 3 & 0 & 53 \\
\hline UnB & 63 & 20 & 16 & 0 & 0 & 67 \\
\hline $\begin{array}{c}\text { PUC } \\
\text { Minas }\end{array}$ & 117 & 38 & 32 & 1 & 0 & 122 \\
\hline PUCRS & 35 & 7 & 9 & 0 & 0 & 33 \\
\hline
\end{tabular}

Fonte: Elaboração própria a partir de dados da Plataforma Sucupira.

Analisando separadamente os dados coletados, percebe-se que as instituições artesanais (apenas USP e UFPR) possuem no período estudado 481 alunos matriculados, contrapondo-se às burocráticas (UFMG, UFSC, Unisinos, PUC Minas, UnB e PUCRS), que juntas acolheram 454 alunos.

É certo que o programa da USP, pela sua amplitude, desequilibra profundamente a análise comparativa empreendida ${ }^{7}$. Neste particular, para um estudo mais refinado e preciso, recomenda-se análise em apartado das duas instituições tipicamente artesanais ainda existentes no Brasil. Caso a política nacional consiga extinguir as duas instituições, isso poderia impedir a oxigenação de todo o sistema. Acredita-se que, para a riqueza e o aperfeiçoamento da política

\footnotetext{
${ }^{7}$ A pós-graduação na USP foi criada em 1969 e o doutorado em Direito implantado em $1^{\circ}$ de janeiro de 1971 , seu programa conta atualmente com onze áreas de concentração, sendo um universo rico que merece, por si só, uma pesquisa própria e detalhada.
} 
Volpato / Metodologia da pesquisa versus pesquisa da metodologia: interfaces da dogmática jurídica na pósgraduação

científica em Direito, as instituições deveriam muito mais primar pela diversidade e criatividade, e bem menos pela massificação e padronização burocráticas.

As artesanais acolheram 27 alunos a mais que as burocráticas, porém titularam 236, enquanto a UFMG, UFSC, Unisinos, PUC Minas, UnB e PUCRS, juntas, no período de 2010 a 2014, titularam bem menos, apenas 167 alunos, isto é, 69 doutores a menos.

\section{Gráfico 8 - Alunos titulados entre 2000 e 2010}

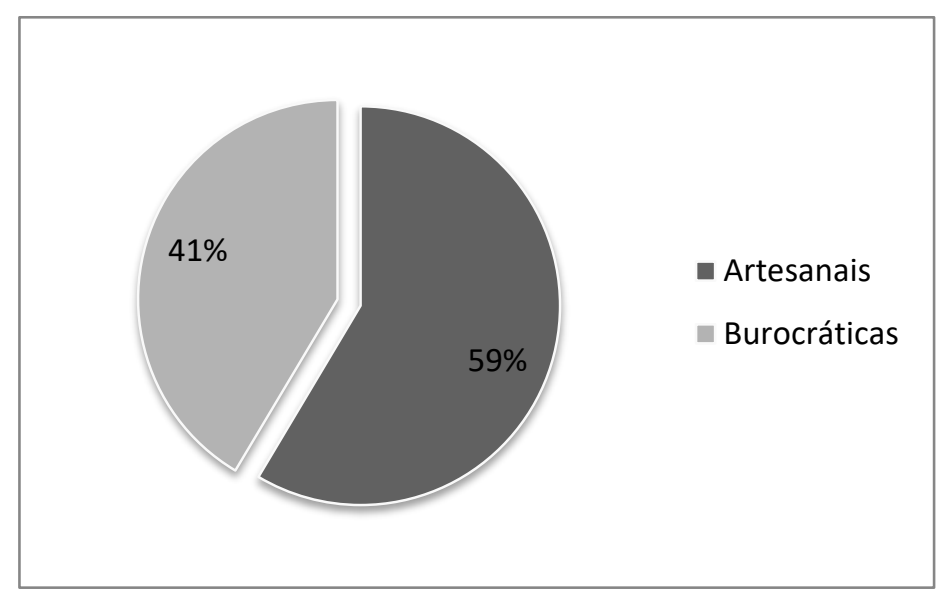

Fonte: Elaboração própria a partir de dados da Plataforma Sucupira.

O nível de eficiência se baseia numa análise numérica por programa. Sujeita a um grau de desproporcionalidade gerado pelo número de alunos acolhidos pelas diferentes instituições de pesquisa. Por ser um dado significativo, recomenda-se para futuras pesquisas, mais minuciosas que esta, que por cautela isolem por estratos mais equânimes ou calculem tal coeficiente seguindo o índice de desproporcionalidade proposto por Gallagher (1991), por exemplo, cujo computo é expresso pela seguinte fórmula:

$$
\mathrm{G}=\sqrt{\frac{1}{2} \sum\left(\mathrm{s}_{\mathrm{i}}-\mathrm{v}_{\mathrm{i}}\right)^{2}}
$$

Onde, com as devidas adaptações:

$\mathrm{vi}=$ percentual de vagas;

si $=$ percentual de teses defendidas.

Este índice foi criado para mensurar a proporcionalidade e a desproporcionalidade dos sistemas eleitorais ${ }^{8}$.

Portanto, contrariando as escolhas administrativas da Capes e das instituições governamentais encarregadas da gestão do conhecimento acadêmico em nível de doutoramento,

8 Recomendando-se a leitura da obra de Gallagher Proportionality, Disproportionality and Electoral Systems, para melhor compreender a presente utilização. 
Volpato / Metodologia da pesquisa versus pesquisa da metodologia: interfaces da dogmática jurídica na pósgraduação

os programas mais eficientes são os da USP e da UFPR, programas artesanais que, na razão entre o número de alunos titulados e matriculados, é $18 \%$ mais eficiente.

O relatório da avaliação de 2010 da área do Direito passou a tocar em uma questão muito delicada: a produção científica publicada em periódicos. Tradicionalmente, esse tipo de publicação era marginal para os juristas, tanto e quanto para as demais humanidades, que preferem adotar como veículos de produção de conhecimento livros ou capítulos de livros (LOPES, 2011, 58).

De fato, a comunicação científica passa a ser importante não só para socializar o conhecimento, mas para o reconhecimento da relevância do trabalho do pesquisador junto à comunidade científica. Assim, uma revista indexada em ambiente virtual é, em potencial, mais facilmente difundida, nacional e internacionalmente, alcançando maior impacto, ou melhor, gerando um impacto quantificável pelo sistema de controle da área.

O sistema de avaliação se demonstra incapaz de mensurar adequadamente a produção real e, indiretamente, tem induzido um comportamento produtivista em potencial. Aumentada a pressão em níveis muito maiores, cresce a necessidade de enfrentar o solipsismo típico da pesquisa jurídica.

\section{CONSIDERAÇÕES FINAIS}

Os métodos e os procedimentos adotados para o desenvolvimento do trabalho científico são imprescindíveis. A extrema importância do método se justifica na medida em que, em caso de inadequação, as conclusões e os achados de uma pesquisa terão pouca validade "científica". O vício no procedimento de pesquisa macula a "cientificidade" de seu esforço. Por essa razão, cabe ao pesquisador o uso preciso de métodos cientificamente aceitos em sua busca de compreensão da problemática de pesquisa escolhida. Um trabalho acadêmico de qualidade, para tanto, precisa articular com clareza tais elementos básicos.

A construção do sentido do discurso científico se evidencia no rigor da apresentação do relatório e nos detalhes dos procedimentos metodológicos adotados. É esse conjunto que imprime confiança, que a pesquisa foi realizada com o zelo necessário, resultados apresentados. Assim, os resultados encontrados, apesar de sugestivos, não podem, de modo indiscriminado, ser aplicados percentualmente a toda produção nacional ou mesmo para a exata precisão da contribuição de cada programa de pós-graduação no panorama nacional.

O intento inicial foi muito mais modesto e preciso, pois se buscou apenas uma amostragem tópica, na qual, quantitativamente, procurar-se-ia avaliar alguns aspectos qualitativos da pesquisa doutoral. E o resultado alcançado se manteve nos limites do estudo assim inicialmente definido. Olhares futuros mais precisos se fazem necessários, seja para investigar a realidade de aspectos pessoais, ou para debruçar-se sobre as realidades institucionais das práticas de pesquisa que são objeto de estudo. Apenas se esforçou para demonstrar de que modo à lógica da racionalidade técnica jurídica se opõe ao desenvolvimento de boas práticas metodológicas, que podem ser mais ousadas e inovadoras. 
Volpato / Metodologia da pesquisa versus pesquisa da metodologia: interfaces da dogmática jurídica na pósgraduação

Estudos anteriores já diagnosticaram que as pesquisas no Direito estão ainda muito centradas na descrição de institutos jurídicos, sem a devida contextualização social. Logo, há necessidade de uma pesquisa-ação em que a definição e a execução participativa de projetos envolvam a comunidade científica e que esteja orientada ao bem comum. Para que o aprimoramento científico das pesquisas jurídicas ocorra, faz-se necessário guardar sintonia com a dinâmica dos projetos político-pedagógicos dos programas de pós-graduação e com as condições de trabalho, seja docente, seja discente.

O desafio de formular melhores perguntas, em especial para estudos mais aprimorados metodologicamente, é uma empreitada não baseada somente nas incertezas, mas na constatação de precarização da universidade pública, da mercantilização da formação profissional e dos imperativos de mercado, já assimilados pela pós-graduação brasileira. Esses fatores precisam fazer eco numa reflexão séria sobre a qualidade da pesquisa jurídica. Assim se explicam os motivos pelos quais a percepção do jurista sobre a questão metodológica na pesquisa do Direito, temática ora escolhida, apesar de central, é praticamente inexplorada pela academia jurídica nacional.

\section{Referências}

ADEODATO, J. M. Bases para uma metodologia da pesquisa em Direito. Revista CEJ, Brasília, DF, v. 7, p. 143-150, jan./abr. 1999.

ATIENZA, M. As razões do Direito: teorias da argumentação jurídica. Tradução de Maria Cristina Guimarães Cupertino. São Paulo: Landy, 2006.

DINIZ, M. H. Compêndio de introdução à ciência do Direito. São Paulo: Saraiva, 1988.

FARIA, J. E. A crise do Judiciário no Brasil: notas para discussão. In: SARLET, I. W. (Org.). Jurisdição e direitos fundamentais. Porto Alegre: Livraria do Advogado, 2006. v. 1. p. 1548.

FRAGALE FILHO, R.; VERONESE, A. A pesquisa em Direito: diagnósticos e perspectivas. RBPG, Brasília, DF, v. 1, n. 2, p. 53-70, nov. 2004.

GALLAGHER, M. Proportionality, disproportionality and electoral systems. ScienceDirect, Amsterdam, v. 10, p. 33-51, mar. 1991. Disponível em: <https://goo.gl/PiZ464>. Acesso em: fev. 2017.

GODOY, A. S. M. Introdução ao realismo jurídico norte-americano. Brasília, DF: Edição do Autor, 2013.

HESPANHA, A. M. Pluralismo jurídico e direito democrático. São Paulo: Annablume, 2013. 
Volpato / Metodologia da pesquisa versus pesquisa da metodologia: interfaces da dogmática jurídica na pósgraduação

LOPES, M. C. B. Entre a estrutura, a estratégia e o discurso: uma análise das práticas do Programa de Pós-Graduação em Direito da UFPR. 2011. 145 f. Tese (Doutorado em Educação) - Pontifícia Universidade Católica do Rio Grande do Sul, Porto Alegre, 2011.

MARSHALL, J. Espadas e símbolos: a técnica da soberania. São Paulo: Editora Revista dos Tribunais, 2008. (RT - Textos Fundamentais, v. 11).

NEVES, A. C. Metodologia jurídica: problemas fundamentais. Coimbra: Coimbra Editoria, 1993.

NOBRE, M. et al. O que é a pesquisa em Direito? São Paulo: Quartier Latin, 2005.

MALHOTRA, N. K. Pesquisa de marketing: uma orientação aplicada. 3. ed. Porto Alegre: Bookman, 2001.

ULEN, T. S. Um Prêmio Nobel para a Ciência Jurídica: teoria, trabalho empírico e o método científico no estudo do direito. In: PORTO, A. M.; SAMPAIO, P. (Org.). Direito e economia em dois mundos: doutrina jurídica e pesquisa empírica. Rio de Janeiro: FGV Editora, 2014. p. 29-92.

VOLPATO, E. C. F. Entre a artesania e a burocracia: ensaio de análise metodológica da pesquisa jurídica doutoral no Brasil no período de 2000 a 2010. 2015. 178 f. Tese (Doutorado em Direito) - Universidade Federal do Paraná, Curitiba, 2015.

Recebido em 12/06/2017

Aprovado em 14/09/2017 
Volpato / Metodologia da pesquisa versus pesquisa da metodologia: interfaces da dogmática jurídica na pósgraduação

Apêndice 1: Teses de doutorado selecionadas por programas de pós-graduação

\section{UFMG}

ALMEIDA, M. V. T. A definição do direito previdenciário complementar na Constituição brasileira. 2001. $341 \mathrm{f}$. Tese (Doutorado em Direito Constitucional) - Universidade Federal de Minas Gerais, Belo Horizonte, 2001. 2 v.

FARIA, J. C. Seguro facultativo de responsabilidade civil: a problemática do direito de ação da vítima contra a seguradora na perspectiva do Código Civil de 2002. 2004. 225 f. Tese (Doutorado em Direito Civil) - Universidade Federal de Minas Gerais, Belo Horizonte, 2004.

GONÇALVES, G. F. M. Observação jurídico-sociológica da lei dos Juizados Especiais Federais. 2007. 144 f. Tese (Doutorado em Direito) - Universidade Federal de Minas Gerais, Belo Horizonte, 2007.

HADDAD, C. H. B. Conteúdo e contornos do princípio contra a auto-incriminação. 2003. 352 f. Tese (Doutorado em Ciências Penais) - Universidade Federal de Minas Gerais, Belo Horizonte, 2003.

JAYME, F. G. A supranormatividade dos direitos humanos. 2003. 386 f. Tese (Doutorado em Direito Constitucional) - Universidade Federal de Minas Gerais, Belo Horizonte, 2003.

HORTA, J. L. B. Horizontes jusfilosóficos do Estado de Direito. 2002. 328 f. Tese (Doutorado em Filosofia do Direito) - Universidade Federal de Minas Gerais, Belo Horizonte, 2002.

LOPES, L. S. A relação entre o tipo legal de crime e a ilicitude: uma análise do tipo total de injusto. 2010. 246 f. Tese (Doutorado em Direito) - Universidade Federal de Minas Gerais, Belo Horizonte, 2010.

MATOS, A. S. M. C. O estoicismo imperial como momento da ideia de justiça: universalismo, liberdade e igualdade no discurso da Stoá em Roma. 2009. 416 f. Tese (Doutorado em Direito) - Universidade Federal de Minas Gerais, Belo Horizonte, 2009.

ROBERTO, G. B. S. O Direito Civil nas academias jurídicas do império. 2008. 608 f. Tese (Doutorado em Direito) - Universidade Federal de Minas Gerais, Belo Horizonte, 2008.

SENA, A. G. A responsabilidade dos sócios em face das obrigações trabalhistas empresariais. 2005. 404 f. Tese (Doutorado em Direito) - Universidade Federal de Minas Gerais, Belo Horizonte, 2005. 
Volpato / Metodologia da pesquisa versus pesquisa da metodologia: interfaces da dogmática jurídica na pósgraduação

\section{USP}

CARVALHO NETO, I. B. A evolução do direito sucessório do cônjuge e do companheiro no direito brasileiro: da necessidade de alteração do Código Civil. 2005. 244 f. Tese (Doutorado em Direito Civil) - Universidade de São Paulo, São Paulo, 2005.

GIL, F. C. A. A onerosidade excessiva em contratos de engineering. 2007. 146 f. Tese (Doutorado em Direito Comercial) - Universidade de São Paulo, São Paulo, 2007.

MARCONDES, R. R. A importância da participação popular na definição do interesse público a ser tutelado pelo Ministério Público do Trabalho. 2010. 189 f. Tese (Doutorado em Direito) - Universidade de São Paulo, São Paulo, 2010.

PAIXÃO, L. A. A função política do Supremo Tribunal Federal. 2007. 258 f. Tese (Doutorado em Direito do Estado) - Universidade de São Paulo, São Paulo, 2007.

ROCHA, J. P. C. V. A capacidade normativa de conjuntura no Direito Econômico: o déficit democrático da regulação financeira. 2004. 204 f. Tese (Doutorado em Direito Econômico e Financeiro) - Universidade de São Paulo, São Paulo, 2004.

SALVADOR NETTO, A. V. Finalidades da pena, conceito material de delito e sistema penal integral. 2008. 297 f. Tese (Doutorado em Direito) - Universidade de São Paulo, São Paulo, 2008.

SANCHEZ, M. R. Demandas por um novo arcabouço sociojurídico na organização mundial do comércio e o caso do Brasil. 2004. 485 f. Tese (Doutorado em Filosofia e Teoria Geral do Direito) - Universidade de São Paulo, São Paulo, 2004.

TAIAR, R. Direito internacional dos direitos humanos: uma discussão sobre a relativização da soberania face à efetivação da proteção internacional dos direitos humanos. 2009. $321 \mathrm{f}$. Tese (Doutorado em Direitos Humanos) - Universidade de São Paulo, São Paulo, 2009.

VERÍSSIMO, M. P. A judicialização dos conflitos de justiça distributiva no Brasil: o processo judicial no pós-1988. 2006. 264 f. Tese (Doutorado em Direito Processual) Universidade de São Paulo, São Paulo, 2006.

ZERBINI, E. C. G. J. O regime internacional dos investimentos: sistemas regional, multilateral, setorial e bilateral. 2003. 250 f. Tese (Doutorado em Direito Interacional) Universidade de São Paulo, São Paulo, 2003. 
Volpato / Metodologia da pesquisa versus pesquisa da metodologia: interfaces da dogmática jurídica na pósgraduação

\section{UFSC}

AGUIAR, J. C. Análise comportamental do Direito: fundamentos para uma abordagem do Direito como ciência comportamental aplicada. 2006. 240 f. Tese (Doutorado em Direito) Universidade Federal de Santa Catarina, Florianópolis, 2006.

APPIO, E. F. O controle judicial das políticas públicas no Brasil. 2004. 473 f. Tese (Doutorado em Direito) - Universidade Federal de Santa Catarina, Florianópolis, 2004.

GOLDSCHMIDT, R. Flexibilização dos direitos trabalhistas: ações afirmativas da dignidade da pessoa humana como forma de resistência. 2008. 253 f. Tese (Doutorado em Direito Constitucional e do Estado) - Universidade Federal de Santa Catarina, Florianópolis, 2008.

MEZZAROBA, O. Da representação política liberal ao desafio de uma democracia partidária: o impasse constitucional da democracia representativa brasileira. 2000. $547 \mathrm{f}$. Tese (Doutorado em Direito) - Universidade Federal de Santa Catarina, Florianópolis, 2000. 2 v.

MICHELS, G. W. O papel da organização mundial do comércio no processo de aproximação das ordens tributárias nacionais. 2009. 269 f. Tese (Doutorado em Direito) Universidade Federal de Santa Catarina, Florianópolis, 2009.

PARDO, D. W. A. Direitos fundamentais não enumerados: justificação e aplicação. 2005. 327 f. Tese (Doutorado em Direito) - Universidade Federal de Santa Catarina, Florianópolis, 2005.

PINTO, A. C. B. O direito paisagístico e os valores estéticos: efetividade e o dano moral coletivo. 2003. 537 f. Tese (Doutorado em Direito) - Universidade Federal de Santa Catarina, Florianópolis, 2003.

SILVA, M. G. Análise crítica da menoridade penal: da exclusão econômico-criminológica à proteção integral. 2010. 107 f. Tese (Doutorado em Direito) - Universidade Federal de Santa Catarina, Florianópolis, 2010.

SILVA, R. P. Reflexões éticas sobre o estatuto da vida: uma abordagem político-jurídica da concepção humana. 2001. 494 f. Tese (Doutorado em Direito) - Universidade Federal de Santa Catarina, Florianópolis, 2001.

VECCHIO, H. P. Justiça distributiva e tributação. 2002. 347 f. Tese (Doutorado em Direito) - Universidade Federal de Santa Catarina, Florianópolis, 2002. 
Volpato / Metodologia da pesquisa versus pesquisa da metodologia: interfaces da dogmática jurídica na pósgraduação

\section{UFPR}

ISFER, E. Sociedade de propósito específico como instrumento de recuperação de empresas. 2006. 348 f. tese (Doutorado em Direito) - Universidade Federal do Paraná, Curitiba, 2006.

GABARDO, E. O jardim e a praça para além do bem e do mal: uma antítese ao critério de subsidiariedade como determinante dos fins do Estado Social. 2009. 412 f. Tese (Doutorado em Direito do Estado) - Universidade Federal do Paraná, Curitiba, 2009.

MARAFFON, M. A. Discursos sobre a verdade, radicalização hermenêutica e fundação ética: o caráter complexo do método jurídico na decisão constitucional. 2004. 262 f. Tese (Doutorado em Direito) - Universidade Federal do Paraná, Curitiba, 2004.

RAMIDOFF, M. L. Direito da criança e do adolescente: por uma propedêutica jurídicoprotetiva transdisciplinar. 2007. 432 f. Tese (Doutorado em Direito) - Universidade Federal do Paraná, Curitiba, 2007.

ROSA, A. M. Decisão no processo penal como bricolage de significantes. 2004. 443 f. Tese (Doutorado em Direito) - Universidade Federal do Paraná, Curitiba, 2004.

SALGADO, E. D. Princípios constitucionais estruturantes do direito eleitoral. 2010. 356 f. Tese (Doutorado em Direito) - Universidade Federal do Paraná, Curitiba, 2010.

PEREIRA, R. C. Princípios fundamentais e norteadores para a organização jurídica da família. 2004. 157 f. Tese (Doutorado em Direito) - Universidade Federal do Paraná, Curitiba, 2004.

PULNER, R. C. L. Análise crítica da cientificidade da legislação relativa a manguezais. 2006. 137 f. Tese (Doutorado em Direito) - Universidade Federal do Paraná, Curitiba, 2006.

VALADÃO, A. R. A. O mínimo existencial e as espécies tributárias. 2008. 347 f. Tese (Doutorado em Direito) - Universidade Federal do Paraná, Curitiba, 2008.

WANDELLI, L. V. O direito ao trabalho como direito humano e fundamental: elementos para sua fundamentação e concretização. 2009. 443 f. Tese (Doutorado em Direito) Universidade Federal do Paraná, Curitiba, 2009.

ZANLORENZI, R. O. R. A significação do real na Teoria do Direito. 2004. 347 f. Tese (Doutorado em Direito) - Universidade Federal do Paraná, Curitiba, 2004. 
Volpato / Metodologia da pesquisa versus pesquisa da metodologia: interfaces da dogmática jurídica na pósgraduação

\section{Unisinos}

ADOLFO, L. G. S. Obras privadas, benefícios coletivos: a dimensão pública do direito autoral na sociedade da informação. 2006. 387 f. Tese (Doutorado em Direito) - Universidade do Vale do Rio Sinos, São Leopoldo, 2006.

BRAGATTO, F. F. Pessoa Humana e direitos humanos na Constituição Brasileira de 1988 a partir da perspectiva pós-colonial. 2009. 269 f. Tese (Doutorado em Direito) Universidade do Vale do Rio Sinos, São Leopoldo, 2009.

BUFFON, M. A tributação como instrumento de densificação do princípio da dignidade da pessoa humana. 2007. $371 \mathrm{f}$. Tese (Doutorado em Direito) - Universidade do Vale do Rio Sinos, São Leopoldo, 2007.

CARVALHO, D. W. Dano ambiental futuro: da assimilação dos riscos ecológicos pelo direito à formação de vínculos jurídicos intergeracionais. 2006. 255 f. Tese (Doutorado em Direito) Universidade do Vale do Rio Sinos, São Leopoldo, 2006.

ESPINDOLA, Â. A. S. Superação do racionalismo no processo civil enquanto condição de possibilidade para a construção das tutelas preventivas: um problema de estrutura ou função? (Ou: por que é preciso navegar em direção à ilha desconhecida e construir o direito processual civil do Estado Democrático de Direito?). 2008. 305 f. Tese (Doutorado em Direito) Universidade do Vale do Rio Sinos, São Leopoldo, 2008.

GIULIANI NETO, R. Imaginário, poder e Estado: o sujeito (sobre)vive. 2008. 204 f. Tese (Doutorado em Direito) - Universidade do Vale do Rio Sinos, São Leopoldo, 2008.

MOTTA, L. F. Tipicidade penal autopoiética. 2008. 274 f. Tese (Doutorado em Direito) Universidade do Vale do Rio Sinos, São Leopoldo, 2008.

NASCIMENTO, V. R. O tempo das reconfigurações do constitucionalismo: os desafios para uma cultura cosmopolita. 2010. 322 f. Tese (Doutorado em Direito) - Universidade do Vale do Rio Sinos, São Leopoldo, 2010.

RECK, J. R. Observação pragmático-sistêmica do conceito de serviço público. 2009. 321 f. Tese (Doutorado em Direito) - Universidade do Vale do Rio Sinos, São Leopoldo, 2009.

SANTOS NETO, A. B. A questão da justiça de Kelsen a Luhmann: do abandono à recuperação. 2009. 324 f. Tese (Doutorado em Direito) - Universidade do Vale do Rio Sinos, São Leopoldo, 2010. 
Volpato / Metodologia da pesquisa versus pesquisa da metodologia: interfaces da dogmática jurídica na pósgraduação

\section{PUC Minas}

ARAÚJO, N. L. Multilateralismo e propriedade intelectual: inserção ativa do Brasil no cenário internacional. 2010. 124 f. Tese (Doutorado em Direito) - Universidade do Vale do Rio Sinos, Belo Horizonte, 2010.

COUTINHO, S. M. B. O Direito das Sociedades Anônimas e a Teoria dos Direitos Fundamentais: uma proposta de leitura constitucional do Direito Societário. 2008. 178 f. Tese (Doutorado em Direito) - Pontifícia Universidade Católica de Minas Gerais, Belo Horizonte, 2008 .

EÇA, V. S. M. Cognoscibilidade da prescrição intercorrente no processo do trabalho constitucionalizado. 2008. 207 f. Tese (Doutorado em Direito) - Pontifícia Universidade Católica de Minas Gerais, Belo Horizonte, 2008.

FARIA, G. N. Teoria jurídica da informação. 2010.169 f. Tese (Doutorado em Direito) Pontifícia Universidade Católica de Minas Gerais, Belo Horizonte, 2010.

FERNANDES, J. C. Cessão fiduciária de títulos de crédito em garantia: a posição do credor fiduciário na recuperação judicial da empresa. 2008. 246 f. Tese (Doutorado em Direito Privado) - Pontifícia Universidade Católica de Minas Gerais, Belo Horizonte, 2008.

NASCIMENTO, A. O. A citação pessoal e válida como elemento do pressuposto processual penal de existência no procedimento em contraditório. 2007. 124 f. Tese (Doutorado em Direito Processual) - Pontifícia Universidade Católica de Minas Gerais, Belo Horizonte, 2007.

NAVES, B. T. O. Revisão crítico-discursiva dos direitos de personalidade - da "natureza jurídica" dos dados genéticos humanos. 2007. 194 f. Tese (Doutorado em Direito Privado) Pontifícia Universidade Católica de minas Gerais, Belo Horizonte, 2007.

SILVA, C. R. V. OACULT: proposta de criação de uma organização internacional de proteção à cultura no âmbito do continente americano. 2009. 127 f. Tese (Doutorado em Direito) Pontifícia Universidade Católica de São Paulo, Belo Horizonte, 2009.

TEIXEIRA, R. P. Legitimação para agir no processo coletivo. 2006. 402 f. Tese (Doutorado em Direito Processual) - Pontifícia Universidade Católica de Minas Gerais, Belo Horizonte, 2006.

UnB

BARBOSA, L. A. A. Mudança constitucional, autoritarismo e Democracia no Brasil pós1964. 2009. 409 f. Tese (Doutorado em Direito) - Universidade de Brasília, Brasília, DF, 2009. 
Volpato / Metodologia da pesquisa versus pesquisa da metodologia: interfaces da dogmática jurídica na pósgraduação

COSTA, A. A. Direito e método: diálogos entre a hermenêutica filosófica e a hermenêutica jurídica. 2008. 421 f. Tese (Doutorado em Direito) - Universidade de Brasília, Brasília, DF, 2008.

MENEZES, O. H. Perfil da propriedade contemporânea (destaque da propriedade fundiária). 2009. 517 f. Tese (Doutorado em Direito) - Universidade de Brasília, Brasília, DF, 2009.

POLETTI, R. R. B. Elementos para um conceito jurídico de império. 2007. 315 f. Tese (Doutorado em Direito) - Universidade de Brasília, Brasília, DF, 2007.

SOUSA JÚNIOR, J. G. Direito como liberdade: o Direito achado na rua. Experiências populares emancipatórias de criação do Direito. 2008. 338 f. Tese (Doutorado em Direito) Universidade de Brasília, Brasília, DF, 2008.

\section{PUCRS}

AVANCINI, H. B. O Direto autoral numa perspectiva dos direitos fundamentais: a limitação do excesso de titularidade por meio do direito da concorrência e do consumidor. 2009. 39 f. Tese (Doutorado em Direito) - Pontifícia Universidade Católica do Rio Grande do Sul, Porto Alegre, 2009.

BARCELLOS, M. L. L. Limites e possibilidades hermenêuticas do princípio da igualdade no direito de patentes brasileiro. 2010. 17 f. Tese (Doutorado em Direito) - Pontifícia Universidade Católica do Rio Grande do Sul, Porto Alegre, 2010.

GERMANO, L. P. R. O direito de resposta proporcional ao agravo: o pleno exercício da liberdade de expressão no Estado Socioambiental e Democrático de Direito. 2010. 25 f. Tese (Doutorado em Direito) - Pontifícia Universidade Católica do Rio Grande do Sul, Porto Alegre, 2010 .

MORAES, V. L. Alcance e limites da atividade jurisdicional na ação civil pública. 2007. 184 f. Tese (Doutorado em Direito) - Pontifícia Universidade Católica do Rio Grande do Sul, Porto Alegre, 2007.

WEINGARTNER NETO, J. A edificação constitucional do direito fundamental à liberdade religiosa: um feixe jurídico entre a inclusividade e o fundamentalismo. 2006. 576 f. Tese (Doutorado em Direito) - Pontifícia Universidade Católica do Rio Grande do Sul, Porto Alegre, 2006. 